\title{
A REFORMA DOS ESTUDOS DE ASSISTENTE DE SERVIÇO SOCIAL NA FRANÇA E SEUS DESAFIOS*
}

\author{
Aline Fino-Dhers ${ }^{1}$
}

\section{RESUMO}

Na França, o decreto $n^{\circ} 2004-533$ de 11 de junho de 2004 e a portaria de 29 de junho de 2004 renovaram o diploma de Assistente do Serviço Social definindo um referencial de competências e modificando a organização dos estágios existentes desde 1981 (Lugar de qualificação - "site qualifiant"- e referente, tutorial). Além disso, a lei da modernização social $\mathrm{n}^{\circ}$ 2002-73 de 17 de janeiro de 2002, com a introdução da validação das aquisições da experiência, abre uma nova via de acesso a esse diploma e, assim, reconsidera um equilíbrio historicamente construído entre a profissão de Assistente do Serviço Social e o Estado.

PALAVRAS-CHAVE: Diploma de Assistente de Serviço Social; França; Referencial de Competências; Aquisição de Experiência.

\section{INTRODUÇÃO}

Não é fácil compreender o dispositivo de formação dos ofícios $\left(\text { métier }^{*}\right)^{2}$ do trabalho social na França. Um relatório recente da Inspection Générale des Affaires Sociales $^{3}$ - Inspeção Geral dos Assuntos Sociais distingue quatro trâmites clássicos correspondentes aos níveis $\mathrm{V}$ a III e conduzem às atividades sociais, educativas, de

\footnotetext{
* * Tradução de Alda Stella Gaspar da Silva. Revisão técnica de Edna Maria Goulart Joazeiro.

${ }^{1}$ Titular do Diploma Superior de Trabalho Social e do D.E.A. da École des Hautes Etudes en Sciences Sociales, foi responsável pela formação superior na Ecole Supérieure de Travail Social em Paris, atualmente é formadora e consultora. Autora do Livro: Assistante Social: un métier entre indétermination et tecnicité, L'Harmattan, 1994. Membro de honra da Association Française pour des Formations Universitaires et Supérieures en Travail Social - AFFUTS - em função de seu trabalho pela criação da Formação Superior em Trabalho Social do $3^{\circ}$ Ciclo na França e pelo apoio à criação da cadeira de Travail Social do CNAM, em Paris, dirigida por Brigitte Bouquet

"Neste texto este termo será traduzido como "Ofício" (N.T.)

2 Termo utilizado na França para designar o conjunto das profissões do setor social do qual faz parte o Serviço Social.

${ }^{3}$ La Documentation Française, L'intervention sociale um travail de proximité. Janvier 2006.

$\begin{array}{llllll}\text { Serviço Social \& Saúde } & \text { Campinas } & \text { v. } 6 & \text { n. } 6 & \text { p. } 1-170 & \text { Maio } 2007\end{array}$
}


ajuda no domicílio e de animação. A estas formações de práticos, se ajuntam os trâmites para as carreiras de gestão e de gerenciamento ou de condução de projetos (diplomas de nível II). Estas formações, na sua maioria, são desenvolvidas em estabelecimentos sob o estatuto de associações sem fins lucrativos ${ }^{4}$ e sob a tutela do Ministère des Affaires Sociales - Ministério dos Assuntos Sociais, mas também no seio das Universidades. Alguns diplomas, particularmente os de nível II, são organizados em colaboração entre Universidades e Centros de Formação particulares e concedem, nesse caso, uma dupla certificação universitária e profissional.

\section{I - NOVA ARQUITETURA DA FORMAÇÃO E VALIDAÇÃO DAS AQUISIÇÕES}

A lei de 13 de Agosto de $2004^{5}$ relativa às liberdades e responsabilidades locais confiou à Região a responsabilidade da definição e aplicação da política de formação dos trabalhadores sociais, assim como a do financiamento da formação inicial e de ajuda aos estudantes ${ }^{6}$. O Plano regional de formação elaborado pelo conjunto dos atores envolvidos é a ferramenta com a qual a Região recenseia as necessidades de formação e indica as modalidades de resposta: meios, prioridades e localização das formações.

Esta transferência de competências às Regiões necessitou de uma recentralização do papel do Estado: todos os diplomas, inclusive o de Assistente de Serviço Social, permanecem nacionais e são emitidos pelo Estado. São instituídos e organizados no âmbito do Ministère des Affaires Sociales (Ministério dos Assuntos Sociais); o Estado controla constantemente os estabelecimentos de formação via

\footnotetext{
${ }^{4}$ Alguns estabelecimentos têm o estatuto do Institute Regionaux de Travail Social (I.R.T.S.).- Institutos Regionais de Trabalho Social; possuem inúmeros campos de estudo. Numerosos centros de formação formam, a partir daí, vários ofícios de trabalho social.

${ }^{5}$ Lei de 13 de agosto de 2004-809 relativa às liberdades e responsabilidades locais.

${ }^{6}$ Informations Sociales $n^{\circ} 135$, octobre 2006, le rôle de la D.G.A.S. au regard de la formation sociale .

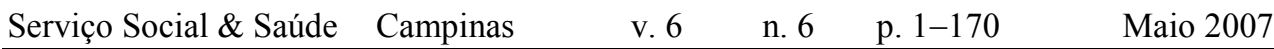


Direction Générale de l'Action Sociale (D.G.A.S): em relação aos programas, qualificação dos formadores e dos diretores de estabelecimentos, assim como a qualidade dos ensinamentos dispensados. A articulação Estado-Região é, de agora em diante, necessária. Um trabalho de renovação dos diplomas de trabalho social foi empreendido sob a égide da D.G.A.S.

Não se trata mais de começar por definir o conteúdo da formação, mas de determinar, primeiramente, os conteúdos do exercício profissional (contexto, função, atividades principais) e as competências profissionais necessárias para exercer este ofício (referencial profissional), as modalidades de validação destas competências (referencial de certificação) e, enfim, a formação permitindo adquiri-las (referencial de formação). Todos os ofícios do trabalho social, inclusive o de Assistente do Serviço Social, estão sendo reconstruídos sob forma de referenciais profissionais (funções atividades e áreas de competência). São diplomas generalistas atestando competências genéricas próprias a cada ofício, aplicadas em diferentes domínios de intervenção para públicos diversificados.

A função qualificante (qualifiante) dos locais (sites) de estágios é reforçada permitindo assim aos empregadores preencherem seu quadro com uma formação profissional em alternância.

Com esse fim foi criada uma Commission Professionnelle Consultative (Comissão Profissional Consultiva) - C. P. C. - do trabalho social e de intervenção social. Ela é composta pelo conjunto de parceiros inter-relacionados: Região, Departamento, Ministérios referidos, parceiros sociais, estabelecimentos de formação. É presidida alternativamente por um representante dos empregadores e um representante dos assalariados. Ela é consultada quanto à oportunidade de realizar trabalhos para reorganizar um diploma. Concede poderes a profissionais que constituem o júri técnico

\begin{tabular}{llllll}
\hline Serviço Social \& Saúde & Campinas & v. 6 & n. 6 & p. 1-170 & Maio 2007
\end{tabular}


encarregado dos trabalhos sob a égide da D.G.A.S. Enfim, dá sua opinião sobre os trabalhos conduzidos.

Esses referenciais são flexíveis o suficiente para que o conteúdo do ensino possa se adaptar aos projetos pedagógicos dos estabelecimentos. As Directions Régionales d'Action Sociale (Direções Regionais de Ação Social) lhes dão apoio técnico e são encarregadas pelo Prefeito da Região de verificar e controlar a conformidade e a qualidade da formação.

Esta renovação dos diplomas que se refere também ao de Assistente de Serviço Social visa a especificar cada ofício do social e, simultaneamente, assinalar as similitudes de competências entre ofícios a fim de organizar as transversalidades entre certificações; ela favorece, assim, a mobilidade dos profissionais e permite trajetórias de formação mais curtas.

Além disso, a validação das aquisições da experiência instituída pela lei de 7 de janeiro de $2002^{7}$ e pelo decreto de 24 de abril de $2002^{8}$ oferece a possibilidade de obter validação parcial ou total de um diploma, justificando no mínimo três anos de experiência profissional em relação com o conteúdo do diploma desejado. A aplicação desta lei aos ofícios do trabalho social suscitou calorosos debates sobre os quais voltaremos.

\section{II - O CONTEÚdO DA REFORMA DOS ESTUdOS DE ASSISTENTE DE SERVIÇO SOCIAL}

A portaria de 29 de junho de 2004, relativa ao diploma de Estado de Assistente de Serviço Social e seus anexos, definem as condições de acesso à formação,

\footnotetext{
${ }^{7}$ Loi de modernisation sociale, du 17 janvier 2002, $n^{\circ} 2002-73$.

${ }^{8}$ Decreto de 24 de abril 2002, n 2002-540 relativo à validação das aquisições de experiência pelos estabelecimentos de ensino superior.

\begin{tabular}{llllll}
\hline Serviço Social \& Saúde & Campinas & v. 6 & n. 6 & p. $1-170$ & Maio 2007
\end{tabular}
}


o conteúdo e a organização da formação. «A formação é distribuída de modo contínuo e descontínuo, em três anos, ou seja, 3540 horas ».

\section{O CONTEÚDO DA FORMAÇÃO}

O ensino teórico é de 1740 horas das quais 450 horas de trabalhos práticos, além de uma formação prática de 12 meses sendo 160 horas efetivas e 110 horas consagradas às relações entre os estabelecimentos de formação e os lugares de qualificação (sites qualifiants).

O ensino teórico se decompõe da forma seguinte:

Uma Unité de Formation Principale - Unidade de Formação Principal (UFP) « teoria e prática da intervenção em Serviço Social » com duração de 460 horas

Sete Unités de Formation Contributives - Unidades de Formação Contributivas (UFC) repartidas entre os ensinos seguintes:

- Filosofia da ação, Ética (120 horas)

- Direito (120 horas)

- Legislação e Políticas Sociais (160 horas)

- Psicologia, Ciências da Educação, Ciências da Informação, Comunicação (120 horas)

- Economia, Demografia (120 horas)

- Saúde (120 horas)

- 200 horas de aprofundamento

- 200 horas destinadas à preparação da certificação.

O ensino teórico não comporta mudanças notáveis. 


\section{A ORGANIZAÇÃO DOS ESTÁGIOS}

Doravante, a duração dos estágios é de 12 meses ao invés de 14 meses, como anteriormente. Um estágio obrigatório de quatro a seis semanas, desde o primeiro ano, deve permitir ao estudante apreender as funções e atividades da profissão e confirmar sua escolha profissional ${ }^{9}$.

Os estágios profissionais são realizados sob a orientação de um referente (référent) Assistente de Serviço Social em 2 ou 3 lugares de qualificação e atuam de forma equivalente na intervenção profissional individual e na intervenção profissional coletiva.

Até então, a organização da acolhida dos estagiários herdada do sistema de 1981 se fazia, majoritariamente, sob a responsabilidade de formadores Assistentes de Serviço Sociais indicados. A reforma põe fim a este dispositivo de aprovação e os estágios se realizam, a partir de então, sob a responsabilidade de "referentes profissionais" («réferent professionnels») designados pela instituição de acolhimento. A exigência de um referente Assistente de Serviço Social é, então, limitada.

Sua missão é assegurar a coordenação entre o serviço de acolhimento, o estabelecimento de formação e o estagiário. Ele assegura o tutorial (novo conceito) do estagiário em colaboração com a equipe ou as equipes pluri-disciplinares ou pluriprofissionais.

Os campos de estágios tornam-se «lugares de qualificação » «sites qualifiants» e são assim reconhecidos como «organizações que ensinam » («organisations apprenantes») a profissionalização tanto no aspecto da prática profissional quanto da aquisição de saberes e de conhecimentos.

\footnotetext{
${ }^{9}$ Rigor implantado pela Direction Générale de l'Action Sociale, em julho de 2004.

$\begin{array}{llllll}\text { Serviço Social \& Saúde } & \text { Campinas } & \text { v. } 6 & \text { n. } 6 & \text { p. 1-170 } & \text { Maio } 2007\end{array}$
}


O lugar de qualificação implica no compromisso da instituição de acolhimento com a formação do estagiário. Os lugares suscetíveis de serem reconhecidos como qualificantes são os serviços sociais polivalentes, os serviços sociais especializados, mas também todos os lugares de acolhimento no campo de intervenção social: albergues, acolhimento diurno, missão local, organismos para a inserção e o emprego.

Uma convenção entre o organismo de acolhimento e o estabelecimento de formação, define os compromissos recíprocos dos signatários. O lugar de qualificação que acolhe os estagiários deve indicar suas áreas de competências e estabelecer um projeto de acolhimento dos estagiários.

\section{A ELABORAÇÃO DE UM REFERENCIAL DE COMPETÊNCIAS}

$O$ anexo I da portaria define o referencial profissional do Assistente de Serviço Social.

O Assistente de Serviço Social exerce de maneira qualificada, no contexto de um mandato e de missões específicas a cada emprego, uma profissão de ajuda definida e regulamentada (artigo I, 411-1 e seguintes do Code d'Action Sociale et des Familles - Código de Ação Social e das Famílias em uma diversidade de instituições, de lugares e de campos de intervenção. Os assistentes sociais e os estudantes que se preparam para o exercício desta profissão se comprometem com o segredo profissional nas condições e sob as reservas enunciadas nos artigos 226-13 e 226-14 do Códe Pénal Código Penal (art. L 411-3 do Code d'Action Sociale et des Familles - Código de Ação Social e das Famílias.

No âmbito das missões que lhe são confiadas, o Assistente de Serviço Social realiza atos profissionais empenhando sua

\begin{tabular}{llllll}
\hline Serviço Social \& Saúde & Campinas & v. 6 & n. 6 & p. $1-170$ & Maio 2007
\end{tabular}


responsabilidade por suas escolhas e suas tomadas de decisão que levam em consideração a lei e as políticas sociais, o interesse dos usuários, a profissão e suas referências práticas e teóricas construídas no curso da história, dele próprio na qualidade de indivíduo cidadão.

Em um percurso ético e deontológico, ele contribui para criar as condições para que as pessoas, as famílias e os grupos com os quais trabalha, tenham os meios de serem atores de seu desenvolvimento e de consolidarem os laços sociais e as solidariedades nos lugares de vida. ${ }^{10}$

\section{O referencial de atividades se enuncia nas funções:}

- Acolhimento / acompanhamento / informação/ orientação

- Mediação

- Acompanhamento social / avaliação/ formação

- Condução de projetos / trabalho com grupos

- Trabalho em rede

Este referencial introduz noções novas como a função de mediação, de acompanhamento social, de avaliação e de trabalho em rede institucionalizando assim, um certo número de práticas já existentes no campo.

\section{$O$ referencial de competências define 4 áreas de competências (DC) :}

- DC1: intervenção profissional em serviço social com duas opções : a condução da intervenção social de ajuda à pessoa e a condução da intervenção de interesse coletivo.

- DC2: avaliação social

\footnotetext{
${ }^{10}$ A integralidade da definição da profissão e dos textos regendo a reforma dos estudos de Assistente de Serviço Social se encontra no site da Association Nationale des Assistants de Service Social (A.N.A.S) www.anas.travail-social.com

$\begin{array}{llllll}\text { Serviço Social \& Saúde Campinas } & \text { v. } 6 & \text { n. } 6 & \text { p. } 1-170 & \text { Maio } 2007\end{array}$
}


- DC3 (transversal) ${ }^{11}$ : comunicação profissional em trabalho social.

- DC4 (transversal): implicação nas dinâmicas em parcerias, institucionais e interinstitucionais.

Este referencial de competências precisa os dois modos de intervenção em Serviço Social: a ajuda à pessoa que é dominante e a intervenção de interesse coletivo, prática ainda pouco desenvolvida na França.

Duas áreas de competências ditas transversais permitem passarelas para outros diplomas em trabalho social e, por conseqüência, reduções da formação. Assim, para os candidatos titulares de um diploma de nível III, as reduções são previstas; elas podem recair sobre as unidades de formação principais ou contributivas, mas não podem exceder os dois terços $(2 / 3)$ da formação teórica.

\section{As modalidades de certificação}

Os candidatos são submetidos a várias provas.

- Uma prova de comunicação realizada em estabelecimento de formação.

- Três provas organizadas em centros de exames inter-regionais

- Uma prova de conhecimento das políticas sociais.

- A apresentação e a defesa de um dossiê de práticas profissionais.

- A apresentação e a defesa de um memorial de iniciação à pesquisa no campo profissional.

Podemos notar duas novidades nas modalidades de certificação: a prova de comunicação e a de conhecimento de políticas sociais.

\footnotetext{
11 Área comum a vários ofícios do social, por exemplo, aos Assistentes do Serviço Social e aos Educadores Especializados.

\begin{tabular}{llllll}
\hline Serviço Social \& Saúde & Campinas & v. 6 & n. 6 & p. $1-170$ & Maio 2007
\end{tabular}
}




\section{A validação das aquisições da experiência: V.A.E.}

A introdução da validação das aquisições da experiência (V.A.E.) na França permite a todas as pessoas, independente de sua idade, seu nível de estudos e de seu status solicitarem a validação de suas experiências e, assim, diminuírem a duração de sua formação.

O artigo 13 precisa as modalidades para a formação de Assistente de Serviço Social :

Os candidatos devem justificar as competências profissionais adquiridas no exercício de uma atividade assalariada, não assalariada ou filantrópica, em relação direta com o diploma de Assistente de Serviço Social.

- Seja pelo menos duas atividades da função « acompanhamento social»

- Seja pelo menos duas atividades da função «condução de projetos e trabalho com grupos»

É uma mudança maior!

Como explicar esta renovação de todos os diplomas de trabalho social e a implantação da validação das aquisições da experiência na França?

Uma breve revisão histórica vai nos permitir compreender como o conjunto do trabalho social que se organizara sob a lógica da qualificação, é submetido, há vários anos, devido a mutações sócio-econômicas, à lógica da competência.

\section{III - O TRABALHO SOCIAL CONFRONTADO À LÓGICA DA COMPETÊNCIA}

Na França, os trabalhadores sociais foram sensíveis à retórica da profissão à medida que sua missão de interesse público diz respeito ao serviço às pessoas. Apesar

\begin{tabular}{llllll}
\hline Serviço Social \& Saúde & Campinas & v. 6 & n. 6 & p. $1-170$ & Maio 2007
\end{tabular}


desta ambição e da existência de algumas características em homologia com a lógica da profissão (em especial para o Serviço Social) os ofícios sociais não chegaram a ser reconhecidos como profissão no sentido pleno.

Certamente, o diploma é indispensável para exercer a profissão, mas esta exigência só é legal para o Serviço Social. Os estudos são relativamente longos, mas não têm reconhecimento universitário exceto quando se faz um duplo curso. ( $\mathrm{O}$ que não é o caso na maioria dos países europeus).

O papel dos profissionais na formação é importante: presença nos júris de entrada e de validação final, a maioria dos «formadores-escola » («formateurs école») são profissionais oriundos do campo, assim como os «formadores-campo» («formateurs-terrain ») encarregados de acompanhar, até aqui, os jovens profissionais em estágio.

Apesar destas convergências, o estatuto de profissões não é reconhecido pelos sociólogos das profissões que as chamam de «quase-profissões ». Duas razões essenciais, entre outras, explicam este estado de fato: estes profissionais são assalariados que dependem das administrações ou do Estado, cada vez com menos autonomia e eles têm, além disso, dificuldade para construir um corpo teórico próprio.

Poder-se-ia dizer, como julga Elisabeth Dugué ${ }^{12}$ que o discurso da profissão desempenhou o papel de logro para o Serviço Social. De fato, as atividades do social são organizadas de modo mais ou menos formalizadas segundo a lógica da qualificação que foi imposta, apesar da explosão de ofícios no campo profissional.

O setor pouco a pouco se homogeneizou graças a uma relação de postos de trabalho pela introdução de convenções coletivas e uma codificação de saberes úteis

\footnotetext{
${ }^{12}$ DUGUÉ E. La compétence: de la rhétorique des professions à la dérégulation de la qualification (A competência : da retórica das profissões à desordem da qualificação), AFFUTS 2000.

$\begin{array}{llllll}\text { Serviço Social \& Saúde } & \text { Campinas } & \text { v. } 6 & \text { n. } 6 & \text { p. 1-170 } & \text { Maio } 2007\end{array}$
}


para construir os diplomas nacionais. A Direction d'Action Sociale (Direção de Ação Social) enquadrou a criação destes diplomas de Estado que são os meios a serviço de uma política nacional de ação social.

Em resumo, a qualificação é uma aquisição histórica para o setor social. Nascido entre filantropia e benevolência, evoluiu, progressivamente, no sentido do assalariamento. É organizado em torno da qualificação cujos principais marcadores são:

- Os diplomas de Estado e as certificações nacionais

- As convenções coletivas.

- Um sistema de formação em alternância com um percurso de estágio acompanhado $^{13}$

A partir do fim dos anos 70, os discursos e as práticas fazendo referência às competências invadiram os espaços de trabalho organizados em torno da qualificação. É uma lógica sustentada pelas direções de empresas e gabinetes de consultores, substituída pelo setor de formação que empreendeu uma profunda modificação na gestão dos recursos humanos.

Vários fatores contribuíram para favorecer a emergência e o desenvolvimento deste modelo da competência:

A transformação da natureza do trabalho:

- Trabalho mais ou menos previsível

- Capacidades novas exigidas: inovação, capacidades relacionadas

- Concorrência exacerbada, portanto aumento na exigência da qualidade

- Mobilidade profissional, flexibilidade

${ }^{13}$ CHAUVIERE M., TRONCHE D. (sous la direction) Qualifier le travail social, dynamique d'un champ professionnel, Paris, Dunod, 2000.

\begin{tabular}{llllll}
\hline Serviço Social \& Saúde & Campinas & v. 6 & n. 6 & p. $1-170$ & Maio 2007
\end{tabular}


A transformação do emprego

- Diversificação das formas de emprego e de contratos de trabalho

- Sub-contratação e prestações de serviço

- A noção de « carreira » parece desaparecer

- Redução das linhas hierárquicas.

As práticas da competência se organizam ao redor de alguns princípios:

\section{Individualização}

Ela impregna toda a gestão de pessoal - a determinação dos salários, a formação, a avaliação das competências, a orientação dos percursos profissionais. Da gestão coletiva das pessoas, passa-se para uma gestão individualizada. As negociações passam do nível nacional para o nível das ramificações até mesmo das empresas.

Os acordos da «competência » ratificam o acordo dos parceiros sociais nas práticas de gestão de carreira em oposição às práticas da qualificação.

As empresas introduzem medidas de gestão para previsão das competências.

\section{A desvalorização dos diplomas}

De fato, os diplomas estabelecidos em nível nacional, são os instrumentos de controle coletivo que contrariam as exigências da lógica da competência. Esta lógica levada ao extremo pode ser hostil aos diplomas que têm somente o poder de atestar o domínio de saberes úteis à atividade profissional.

De fato, o novo contexto de trabalho exige que os assalariados não somente possuam conhecimentos, mas, sobretudo que se adaptem, rapidamente, às evoluções da empresa e que sejam, imediatamente, « operacionais».

\begin{tabular}{llllll}
\hline Serviço Social \& Saúde & Campinas & v. 6 & n. 6 & p. $1-170$ & Maio 2007
\end{tabular}




\section{A adaptação do pessoal às flutuações dos sistemas de trabalho}

Face ao trabalho cada vez menos previsível, os funcionários móveis e sem estatuto regulamentado permitem fazer face à flexibilidade que passa a ser exigida das empresas.

\section{A valorização dos saberes resultantes da experiência prática}

Encontramos aqui um empréstimo da retórica das profissões e um discurso familiar ao trabalho social: valorização da prática, da experiência, do efeito formador das situações de trabalho, dos valores da autonomia, da responsabilidade.

Mas a gestão pela competência preconizada em toda a França, inclusive nas organizações públicas, provoca numerosos debates e alimenta uma tripla reflexão.

- Sobre a dimensão metodológica: como definir e avaliar as competências em um setor de atividade? Com qual metodologia? Qual deontologia e quais ferramentas?

- Sobre os aspectos sócio-organizacionais: impacto sobre os princípios e a gestão de pessoal (validação de aquisições, validação das competências, recrutamento, mobilidade).

- Sobre a formação (papel dos diferentes atores, organização, modalidades de acesso, avaliação).

\section{IV - IMPACTO DA LÓGICA DA COMPETÊNCIA SOBRE A FORMAÇÃO}

\section{A valorização da prática profissional e da experiência}

A aplicação da validação das aquisições da experiência para vários diplomas ao lado da formação inicial, da aprendizagem e da formação profissional contínua

\begin{tabular}{llllll}
\hline Serviço Social \& Saúde & Campinas & v. 6 & n. 6 & p. $1-170$ & Maio 2007
\end{tabular}


constitui, a partir de então, uma quarta via de acesso aos diplomas, títulos ou certificados de qualificação profissional na França.

Vários diplomas já dizem respeito a nosso setor: Auxiliar de Vida Social, Educadores Especializados, Assistente de Serviço Social, Organizador de Proximidade, Mediador Familiar. Sua aplicação não parece ser das mais fáceis.

Ela apresenta vantagens à medida que favorece a promoção social e é uma solução para a carência de pessoal qualificado no setor sanitário e social (numerosas aposentadorias). Além disso, ela permite a aquisição de uma certificação para o pessoal que « exerce a função » há muitos anos no setor educativo; entretanto, ela representa um risco real de «rebaixar a formação » reduzindo a duração e, consequentemente, os custos do curso em relação à formação inicial.

Além disso, se a V.A.E. não reconsidera em princípio o estatuto dos saberes e dos conhecimentos, ela o torna relativo. Ora, os saberes teóricos são importantes para os práticos à medida que lhes permitem compreender a lógica subjacente à sua ação.

\section{VANTAGENS E RISCOS DA ABORDAGEM PELA COMPETÊNCIA}

Certamente, a definição de referenciais tem o mérito de objetivar os ofícios que, por muito tempo, recusaram a descrever, explicitamente e sistematicamente, sua prática considerada como desprezível.

Certamente, a abordagem pela competência favorece o desenvolvimento de comportamentos ligados à resolução de problemas ou à comunicação operacional. Mas é totalmente insuficiente para os ofícios sociais, pois a dimensão simbólica da prática escapa a esta abordagem. 
Além disso, os referenciais induzem a um modelo de formação modular no qual as aquisições são pensadas de maneira linear e mecânica, esquecendo a existência de uma dimensão, algumas vezes, conflitantes na situação de aprendizagem.

Se formar depende de um processo, ou seja, de um percurso ordenado segundo uma certa lógica progressiva que foi pensada e organizada sobre uma duração para atingir um certo resultado. De fato, corremos o risco de nos distanciarmos de um modelo de formação em alternância desejado, com uma pedagogia verdadeira de alternância, estruturado ao redor de uma lógica de conhecimento. Os conceitos explicativos com referência aos campos disciplinares servem para esclarecer, analisar as situações profissionais para isolar o sentido da ação e transformar nosso sistema de representações sociais, único meio para mudar nossa visão da realidade e agir de modo diferente.

Destacar as situações de trabalho nos adverte Elisabeth Dugué ${ }^{14}$, é colocar em evidência as atitudes e o comportamento com o risco de esquecer os saberes teóricos e a reflexão sobre o ato de trabalho. A espera implícita da abordagem pela competência, é a adaptação do pessoal às flutuações dos sistemas de trabalho. As atividades evoluem em permanência em um campo de trabalho cada vez mais indeterminado.

Antigamente, se privilegiava a espera de desempenhos ligados a um emprego. Hoje, se deseja as competências ditas «transversais » para favorecer a mobilidade dos assalariados no seio da organização e nos espaços de trabalho cada vez maiores na escala européia. Enfim, o último risco: ao lado de um dispositivo de formação coletiva onde o grupo desempenha um papel essencial para a dinâmica formativa, vão se inserir

\footnotetext{
${ }^{14}$ DUGUE, E. La gestion des compétences, les savoirs dévalués, le pouvoir occulté, in Sociologie du travail, $n^{\circ} 3 / 1994$.
} 
percursos individualizados escolhidos livremente pelos estudantes que vão participar de um ou de vários módulos sem necessariamente compreender o sentido global do processo de formação.

\section{A ABORDAGEM PELA COMPETÊNCIA E A EUROPA}

Ela se reveste de um interesse particular no momento em que se constrói a reforma universitária LMD (licenciatura, mestrado, doutorado) visando a harmonização dos diplomas universitários sobre um plano europeu: o Processo de Bologne (Processus de Bologn), que começou em 1999, introduziu o Système Européen de Transfert et d'Accumulation de Crédits (Sistema Europeu de Transferência e de Acúmulo de Créditos) - E.T.C.S.

É preciso saber que uma estratégia idêntica existe a favor da formação profissional e da mobilidade com a perspectiva de um mercado de trabalho europeu aberto a todos. A conferência de Copenhague em 2002 reforçou a cooperação no domínio do ensino e da formação profissional e implantou um outro sistema de créditos European Credits for Vocational Education and Training (Créditos Europeus para Educação Vocacional e Treinamento) - E.C.V.T. - Cada país é convidado a elaborar um quadro nacional de qualificações que é a referência para comparar os conjuntos nacionais de qualificações e cada ramificação deve estabelecer um referencial de competências.

É difícil saber sobre quais sistemas vão se « fixar » nossas formações sociais que dependem da formação profissional, mas que são, algumas vezes, articuladas aos diplomas universitários enquanto que na Europa a formação dos ofícios sociais é organizada na universidade na maioria dos países, ou então, ela depende de Hautes Ecoles profissionais como é o caso da Suíça e da Bélgica.

\begin{tabular}{llllll}
\hline Serviço Social \& Saúde & Campinas & v. 6 & n. 6 & p. $1-170$ & Maio 2007
\end{tabular}




\section{V - EM DIREÇÃO A UMA NOVA DEFINIÇÃO DA FORMAÇÃO}

A reforma dos estudos do diploma de Assistente de Serviço Social pelas diferentes inovações que introduz, desestabiliza um equilíbrio, historicamente, construído ao redor da lógica da qualificação. Ela vem perturbar um processo de controle coletivo entre o Estado e a profissão o qual controlava a definição do ofício através da organização da formação.

A atribuição de diplomas a pessoas que seguiram caminhos profissionais menos ortodoxos ou diferentes da forma tradicional é suscetível de constituir uma ocasião de abertura da profissão e não uma reconsideração de sua unidade ${ }^{15}$.

Mas a abertura, como toda mudança maior, comporta um risco que exige compreender os desafios implícitos subjacentes a esta reforma. Por trás dos conceitos de competência, de organização que ensina, de lugar de qualificação, de experiência se projetam referências teóricas saídas do aprendizado organizacional ${ }^{16}$ e uma concepção nova da formação nas e pelas situações de trabalho.

As modalidades de formação vão mudar radicalmente, à medida que o lugar de estágio adquire uma legitimidade nova em matéria de formação. O próprio lugar onde se exerce a atividade é reconhecido como lugar de qualificação, o que quer dizer que ele deve desenvolver dispositivos de formação integrados ao trabalho.

No setor social, estivemos até aqui em uma pedagogia do modelo onde a identificação com o profissional da mesma categoria era primordial. O estágio exigia um posicionamento próximo de um profissional com um trabalho de análise da prática, uma avaliação final ao olhar de objetivos pré-definidos. O centro de formação

\footnotetext{
${ }^{15}$ MERLE V. La validation des acquis de l'expérience dans le travail social, in Informations Sociales $\mathrm{n}^{\circ} 135$ / octobre 2006.

\begin{tabular}{llllll}
\hline Serviço Social \& Saúde & Campinas & v. 6 & n. 6 & p. $1-170$ & Maio 2007
\end{tabular}
}


intervinha no campo por ocasião de uma visita de estágio no âmbito de uma avaliação tripartite.

Doravante, o centro de formação não tem mais a exclusividade da formação; à medida que as competências não podem se construir e só se aprofundar dentro de uma situação concreta de trabalho, o lugar de qualificação torna-se um parceiro essencial da formação.

A formação é, de agora em diante, uma preocupação partilhada entre centro de formação e lugar de qualificação, entre formadores da escola e referente, entre referente e equipe pluriprofissional.

Ela exige um compromisso da organização que acolhe o (ou os) estagiário (s) que se concretizará por uma convenção e um projeto de acolhimento do estagiário definindo as áreas de competências sobre os quais se engaja ao lugar de qualificação.

É evidente que estes novos atores: lugar de qualificação e referente profissional vai obrigar os atores tradicionais: centros de formação, formadores da escola, formador do campo a se [re]posicionarem.

A finalidade da formação torna-se a produção de competências necessárias ao domínio das situações profissionais e de sua evolução. A formação deve ser combinada com outros fatores necessários à produção das competências: estímulo da motivação, meios materiais, acompanhamento cuja introdução depende da responsabilidade do referente. A formação, então, tem por objetivo preencher a distância entre competências adquiridas e competências necessárias; o que supõe reconhecer a montante esta distância e nomeá-lo no projeto de acolhimento do estagiário sob forma de conhecimentos a adquirir, de saber-fazer, de atitudes ou de comportamentos.

16 Ver as obras: ARGYRIS C. Savoir pour agir, surmonter les obstacles à l'apprentissage organisationnel, Paris, Interéditions, 1995 - ARGYRIS C. et Schön D. Apprentissage organisationnel, théorie, méthode, pratique, Bruxelles, de Boeck, 2002.

$\begin{array}{llllll}\text { Serviço Social \& Saúde } & \text { Campinas } & \text { v. } 6 & \text { n. } 6 & \text { p. } 1-170 & \text { Maio } 2007\end{array}$


A formação se apóia sobre situações de trabalho transformadas em situações formativas. O referente, em colaboração com a equipe que anima, deve identificar situações de trabalho sensíveis de serem «formativas » em relação aos domínios de competências pré-definidos enquanto lugar de qualificação e deve facilitar o posicionamento do estagiário.

O que é uma situação de trabalho formativa? Como o trabalho é formador?

Tornar o trabalho formador consiste em escolher e preparar seqüências de trabalho, explicitar e mostrar o trabalho, fazer executar o trabalho sob controle, isto é, observar no momento do início de sua realização ou analisá-lo a posteriori.

Esta postura pedagógica apresenta várias inovações: a implicação do lugar de qualificação, parceiro da formação e a transformação do acompanhamento. É um acompanhamento coletivo onde um referente e uma equipe partilham certas seqüências formativas.

É um tutorial que se exerce a partir de situações de trabalho formativas. Isto significa que os profissionais devem ser capazes de conceituar a prática profissional, de pensá-la não mais em termos de tarefas a executar, mas de conceber o porquê e como e sobre quais aspectos a postura de uma permanência, por exemplo, pode ser uma situação de aprendizagem para um estagiário.

As exigências ligadas à reforma são importantes também para a organização que ensina: tornar a organização que ensina é de fato um objetivo de longo prazo que supõe favorecer o trabalho em rede e em equipe, introduzir uma prática contínua de avaliação e um sistema de capitalização dos conhecimentos e do saber-fazer. Este capital imaterial torna-se então uma fonte de eficiência para a organização.

Esta reforma dos estudos introduz rupturas ao mesmo tempo para os centros de formação e para as organizações e, pode-se falar de revolução cultural. Ela exige, de

\begin{tabular}{llllll}
\hline Serviço Social \& Saúde & Campinas & v. 6 & n. 6 & p. $1-170$ & Maio 2007
\end{tabular}


uns e de outros, uma preparação séria para manter uma qualidade da formação e do acompanhamento dos jovens profissionais do setor social.

É enfim fazer a aposta de que, apesar da diversidade dos percursos e das modalidades de aprendizagem, pode-se construir uma identidade profissional comum dos Assistentes do Serviço Social.

\begin{abstract}
In France, the decree 2004-533 of June 11, 2004 and the edict of June 29, 2004 have improved the social worker certificate by defining a referential of competences and modifying the organization of the apprentices existing since 1981. Moreover, the social modernization's law $n^{\circ} 2002-73$ of January 17, 2002, through the introduction of the experience's acquirement validation, opens a new way for reaching that certificate and, thus, thinks over again the equilibrium historically constructed between the social worker profession and the state.
\end{abstract}

KEYWORDS: Social Worker Certificate; France; Referential of Competences; Experience Acquirement.

\title{
REFERÊNCIAS BIBLIOGRÁFICAS
}

AGYRIS, C. Savoir pour agir, surmonter les obstacles à l'apprentissage organisationnel, Paris : Interéditions, 1995.

ARGYRIS C. Schön D. Apprentissage organisationnel : théorie, méthode, pratique, Bruxelles : de Boeck, 2002.

CHAUVIERE, M. Tronche D. (Sous la direction) Qualifier le travail social, dynamique professionnelle et qualité de service, Dunod, 2002.

CHOPART, J.N. (Sous la direction) Les mutations du travail social, dynamique d'un champ professionnel, Dunod, 2000.

DUGUE, E. La gestion des compétences, les savoirs dévalués, le pouvoir occulté, in: Sociologie du Travail, $\mathrm{n}^{\circ} 2-1996$.

DUGUE, E. La compétence: de la rhétorique des professions à la dérégulation des qualifications, Conférence à AFFUTS, 2000.

\begin{tabular}{llllll}
\hline Serviço Social \& Saúde & Campinas & v. 6 & n. 6 & p. $1-170$ & Maio 2007
\end{tabular}




\section{REVISTAS}

LES CAHIERS N 3 AVEC FINO-DHERS A. Freynet M. F. Hatzfeld H. Jaegger M. Ladsous J. Sigala C. Trapon M. Valette J.C. 2000.

INFORMATIONS SOCIALES, ${ }^{\circ} 135$, octobre 2006, Enseigner le social.

\section{RELATÓRIOS}

LA DOCUMENTATION FRANÇAISE, l'intervention sociale un travail de proximité, janvier 2006. 